\title{
Determinants of employment-based private health insurance coverage in Denmark
}

\author{
ASTRID KIIL* \\ kii@sam.sdu.dk \\ University of Southern Denmark
}

\begin{abstract}
This study estimates the determinants of having employment-based private health insurance (EPHI) based on data from a survey of the Danish workforce conducted in 2009. The study contributes to the literature by exploring the role of satisfaction with the tax-financed health care system as a potential determinant of EPHI ownership and by taking into account that some employees receive EPHI free of charge, while others pay the premium out of their pre-tax income and thus make an actual choice. The results indicate that the probability of having EPHI is positively affected by private sector employment, size of the workplace, whether the workplace has a health scheme, income, being employed as a white-collar worker, and age until the age of 49 , while the presence of subordinates, gender, education level, membership of 'denmark' and living in the capital region are not significantly associated with EPHI coverage. As expected, the characteristics related to the workplace are by far the quantitatively most important determinants. The association between EPHI and self-assessed health is found to be quadratic such that individuals in good self-assessed health are more likely to be covered by EPHI than those in excellent and fair, poor or very poor self-assessed health, respectively. Finally, the probability of having EPHI is found to be negatively related to the level of satisfaction with the tax-financed health care system. The findings of the study are not affected notably by distinguishing empirically between employees who receive EPHI free of charge and those who pay the premium out of their pre-tax income.
\end{abstract}

Keywords: Duplicate health insurance; Determinants; Inequity in access; Health care satisfaction; Denmark

\section{Introduction}

In several European countries with universal tax-financed health care systems, such as the United Kingdom, Spain, and the Scandinavian countries, considerable parts of the populations now have private health insurance that covers treatment at private facilities (Aarbu, 2010; Mossialos and Thomson, 2002). Hence, the analysis of this type of private health insurance is of both theoretical and policy relevance. Private health insurance that covers treatment at private facilities for treatment that is also available free of charge at public hospitals may be classified as duplicate vis-a-vis the universal system. The main perceived benefits are faster access to care, greater freedom of choice, and in some cases also better amenities (Colombo and Tapay, 2004; OECD, 2004). 
As reviewed by Propper and Green (2001), private funding in public health care systems may have several possible consequences. On the one hand, duplicate private health insurance may be thought of as accommodating differences in preferences, and it allows for greater freedom of choice than would be feasible in a purely tax-financed system with only public hospitals. Moreover, it may relieve the pressure on the public system and reduce the waiting times for treatment at public facilities, which in turn may decrease sickness absence to the extent that this is associated with waiting time for treatment. On the other hand, the main arguments against private health insurance are that it may cause inequity in the access to medical care and possibly also increase the total medical spending due to moral hazard and dynamic effects on wages in the health care sector. In the longer run, increasing reliance on private health insurance may also bring about reduced support for the universal health care system, thereby possibly worsening the access to health care for the individuals who rely exclusively on this.

While the determinants of individually purchased duplicate private health insurance have been studied extensively in the literature, empirical evidence on what characterises the group of individuals with policies that are purchased through and typically also paid by their employer is confined to a few studies. ${ }^{1}$ This paper contributes to the growing literature on employment-based private health insurance (EPHI) in universal tax-financed health care systems based on a recently collected dataset from Denmark.

The share of the occupationally active Danish population with EPHI has increased steadily during the past decade. Following legislation enacted in 2002 that tax-exempted employees for the income value of EPHI conditional on the insurance being offered to all employees in the company, the share with EPHI has gone from 5 percent to 32 percent of the employed in 2009 (Statistics Denmark, 2010; The Danish Insurance Association, 2010). The purpose of the tax-exemption was to make it more attractive for employers to assume a social responsibility and to improve the overall welfare by reducing waiting times for treatment at public facilities and decreasing sickness absence. In addition, it was hoped that making the tax-exemption contingent on the insurance being offered to all employees in the company would induce a more equal distribution of EPHI within the companies (The Danish parliament, 2002). ${ }^{2}$ Premiums are either fully paid by the employers or (for about 26 percent of the insured based on the data used in this paper) deducted from the pre-tax income of the employees. The EPHI contracts available in the Danish market primarily cover diagnostics and elective surgery at private facilities for treatments that are also available at public hospitals, but often with some waiting time (The Danish Insurance Association, 2010). Hence, as noted above, they may be classified as primarily duplicate in relation to the tax-financed health care system.

\footnotetext{
${ }^{1}$ Empirical studies of the determinants of individually purchased private health insurance include, but are not limited to, Besley et al. (1999), Costa and Garcia (2003), Harmon and Nolan (2001), Jofre-Bonet (2000), King and Mossialos (2005), Olivella and Vera-Hernández (2006), Propper (1989), Propper et al. (2001), and Rodríguez and Stoyanova (2008). Empirical studies of the determinants of employment-based private health insurance are confined to Aarbu (2010), Besley et al. (1999), Bræmer (2008), Grepperud and Iversen (2011), King and Mossialos (2005), Kjellberg et al. (2010), and Seim et al. (2007). These studies are reviewed in section 4.

${ }^{2}$ The condition that the insurance should be offered to all employees in a company in order to qualify for the tax-exemption was not included in the initial bill, but added during the readings of the bill (The Danish parliament, 2002).
} 
The distributional consequences of EPHI may be assessed based on the principle of horizontal equity in the access to health care, which implies equal access to treatment for individuals in equal need. The condition that the insurance should be offered to all employees in a company in order to qualify for the tax-exemption may well be expected to eliminate horizontal inequity within companies. Defining horizontal inequity as any differences, EPHI generates horizontal inequity in the access to health care between those in the workforce holding EPHI and those not holding EPHI by definition, by allowing individuals with the same need for health care to differ in their access to treatment depending on insurance status. However, another frequently used approach is to consider horizontal inequity as differences in access or use that vary systematically with sociodemographic determinants. Following this approach, there is inequity in the access to health care when access varies systematically with sociodemographic determinants; while randomly distributed differences do not by themselves imply inequity. Regardless of which approach is used, the presence of EPHI generates horizontal inequity between the workforce and students, pensioners, and unemployed, who do not have EPHI through their workplace by definition.

Theoretically, insurance status is the outcome of a decision process encompassing the choice of employer, the decisions of the employer to employ the employee and to offer private health insurance, and in some cases also the decision of the employee to accept or reject this offer. When insurance premiums are fully paid by employers, the insurance status of the employees is predominantly determined by the decision of the employer to offer EPHI. On the contrary, when the premium is deducted from the pre-tax income of the employees, they face an actual choice and may reject the insurance offer. ${ }^{3}$ Hence, the decision framework as well as the determinants may well differ depending on whether the insurance premium is fully paid by the employer or deducted from the pre-tax income of the employee.

The aim of this paper is to estimate the determinants of EPHI coverage within the Danish workforce. Given the expectation from political side that making the taxexemption contingent on the insurance being offered to all employees would induce an equal distribution of EPHI coverage within companies, and preferably also reduce the importance of socioeconomic determinants in the distribution of EPHI within the workforce, knowledge on the resulting determinants of EPHI is highly relevant for Danish policy-makers. The paper contributes to the international literature in two ways. For one thing, it is the first study to explore the role of satisfaction with the tax-financed health care system as a potential determinant of EPHI coverage. From a theoretical point of view, companies and employees who are unsatisfied with the public system may reasonably be expected ascribe greater value to duplicate private health insurance. Secondly, it is explored whether the main results change when taking into account that some employees receive the insurance free of charge, while others pay the premium out of their pre-tax income, thus also making a choice at the individual level. To the best knowledge of the author, this study is the first to make such distinction, which may be crucial given that the decision framework differs for the two cases.

\footnotetext{
${ }^{3}$ A telephone survey of HR-staff in several larger companies offering EPHI which is paid for by the employees by having the premium deducted from their pre-tax income confirmed that in this case EPHI is always presented as an optional choice and the employees are required to make an active choice. Hence, it may reasonably be expected that the employees do perceive that they face an actual choice and may reject the offer in this case.
} 
The paper is organised as follows. Section 2 describes the development of EPHI and its institutional setting in Denmark. Section 3 accounts for the theoretical framework of the decision process that leads to EPHI coverage. The purpose of this section is not to develop new theory, but to provide an overview of the existing framework. Section 4 summarizes the empirical knowledge about the determinants of EPHI in universal health care systems. Section 5 describes the data used in the empirical analysis, accounts for expected associations between explanatory variables and EPHI coverage, and provides some descriptive evidence. Section 6 accounts for the econometric specification. The results are reported in section 7. Section 8 discusses possible interpretations and implications of the results as well as the limitations of the study. Section 9 concludes.

\section{Institutional setting}

The Danish health care system is a comprehensive tax-financed system with universal access. General practitioner and specialist visits, out-patient ambulatory care as well as hospitalisations are free at the point of use for all citizens. General practitioners act as gatekeepers in the sense that in most cases a referral from a general practitioner is needed to be able to access more specialised treatment. Copayment and waiting time are frequently used to ration the use of health care services for which demand is price or time sensitive. There is considerable private copayment for adult dental care, prescription medication, physical therapy, chiropractic care, and psychological counselling (Strandberg-Larsen et al., 2007). Private copayment accounted for about 14 percent of total health expenditures in 2009 (OECD, 2009). For other types of treatment, mainly elective surgery, there may be waiting time for treatment at public hospitals. This has attracted considerable public and political attention over time (Madsen, 2010).

The EPHI policies available in the Danish market are supplied by commercial insurance companies. The exact benefits differ slightly between insurance companies, just like policies are often tailored to specific firms. EPHI is mainly offered in the private sector. As previously mentioned, the EPHI contracts available in the Danish market primarily cover diagnostics and elective surgery at private facilities for treatments that are also available at public hospitals, but often with some waiting time. ${ }^{4}$ In addition, EPHI is increasingly used to finance health care services for which private copayment is common in the public sector, such as physiotherapy, chiropractic care, and psychological counselling (The Danish Insurance Association, 2010). In 2009, the total gross compensations paid out by the commercial insurers were distributed as follows: 67 percent covered operations and the like, 9 percent covered psychologist consultations, 17 percent covered physiotherapy, chiropractic care and the like, and 7 percent covered other services (The Danish Insurance Association, 2010).

Gross compensations from private health insurance (individually purchased and employment-based) make up 1.6 percent of the total Danish health expenditure (OECD, 2010).

As previously mentioned, premiums are either paid by employers or (for about 26 percent of the insured based on the data used in this paper) deducted from the pre-tax income of the employees. The premium for fully employer paid insurance is not, like the value of many fringe benefits, subject to income tax when insurance is offered to all

\footnotetext{
${ }^{4}$ However, given that hospital waiting times have declined in recent years among other things due to the introduction of free hospital choice (Kjellberg et al., 2010), some commentators might argue that duplicate EPHI in fact does not imply quicker access to hospital care anymore (thanks to an anonymous reviewer for pointing this out).
} 
employees in a company. ${ }^{5}$ This implies an indirect tax subsidy of about 40-60 percent of the premium depending on the taxable income of the employee. The annual premium per employee varies depending on the benefit scheme and the size of the workplace. Larger companies generally pay a smaller premium per employee because the scope for risk pooling increases with company size. There is no risk rating of premiums within companies due to the conditions of the tax-exemption; it is, however, likely to occur between companies. The average premium per person has been constant around DKK 1000/EUR 134 since 2003, but increased to DKK 1428/EUR 191 in 2009 (The Danish Insurance Association, 2010). ${ }^{6}$

While it is possible that screening of firms occurs, insurance eligibility within the firm is usually not conditional on health status. However, there may be a deferred period for treatment of existing conditions and limitations on the annual number of consultations with physiotherapists, chiropractors, and psychologists. Moreover, private insurance patients are subject to gate keeping given that coverage is contingent on having a documented need for treatment (The Danish parliament, 2002). For private hospital treatment, need is typically documented by obtaining a referral from a general practitioner.

Duplicate private health insurance can also be purchased from the commercial insurance companies on an individual basis. The benefits are roughly the same as for the employment-based contracts, but premiums are not subject to special tax treatment and are risk rated based on age. Existing conditions are usually excluded from coverage. According to industry numbers, approximately 100,000 individuals had taken out private health insurance through a commercial insurance company on an individual basis in 2009 (The Danish Insurance Association, 2010).

In addition to EPHI, some employers also have company health schemes in place, which provide prevention and treatment of work-induced injuries, typically with physiotherapy, chiropractic care, massage, and reflexology. The health schemes differ from EPHI in the sense that they do not provide any type of elective surgery at private facilities, and that they treat only work-induced injuries.

Finally, more than two million Danes (approximately 42 percent of the adult population) have taken out private health insurance through the non-profit mutual insurance company 'denmark' in 2009 (Health Insurance denmark, 2009). This type of private health insurance is mainly complementary to the tax-financed health care system in that it primarily covers copayments for treatment in the public health care system. Approximately 25 percent of the members of 'denmark' are also partly reimbursed for elective surgery at private hospitals (according to internal material from 'denmark').

Despite some overlap in the coverage between the individually purchased and employment-based insurance contracts, some individuals hold both. In the sample described in section 5.1, 23 percent of the respondents are covered by both EPHI and 'denmark'. One obvious reason for this is that employees are not very likely to reject an offer of practically free EPHI even though they are already covered through 'denmark'. Another possible and likely reason is that the EPHI contracts usually expire when the

\footnotetext{
${ }^{5}$ The legislative framework opens up for that companies may differentiate somewhat in the health benefits offered to their employees based on seniority and number of working hours and maintain the tax exemption (Danish Tax and Customs Association, 2005). This option is, however, not likely to be widely used due to the administrative costs of this.

${ }^{6}$ The figures are calculated as total premium income of the commercial insurers divided by the number of insured. Conversion from DKK to EUR is undertaken using the March 2011 average exchange rate of 745.74 (Danske Bank, 2011).
} 
insurance holder changes job or retires, while insurance through 'denmark' is life-long with a fixed premium. Moreover, the EPHI policies do not cover copayment for some treatments provided within the tax-financed health care system, such as adult dental care and prescription drugs, which are the most important benefits covered by 'denmark'. The determinants of membership of 'denmark' are not subject to analysis in this paper; its existence is, however, taken into account when analysing determinants of EPHI.

\section{Theoretical framework}

The insurance status of an employee is the outcome of a decision process encompassing the individual's choice of employer, the decision of the employer to employ the employee and to offer EPHI, and in some cases also the decision of the employee to accept or reject the offer. While EPHI has been found to have important implications for labour market choices in the US (Currie and Madrian, 1999), it is not expected to notably affect labour market choices in Denmark, where the value of EPHI makes up a negligible small share of the total compensation package. ${ }^{7}$ Hence, this part of the decision process is not considered in the following. Moreover, the theoretical literature on private health insurance in general and EPHI in particular mainly takes its point of departure in the US health care system, where EPHI provides the primary source of coverage for all health care (i.e. both acute and elective) for the working age population. This must be kept in mind when applying the theories outlined in the following to settings where private insurance provided through the workplace primarily covers elective surgery at private hospitals and clinics for treatments that are also available at public hospitals.

When insurance premiums are fully paid by employers and tax-exempted, the insurance status of the employees is predominantly determined by the decision of the employer to offer EPHI. Section 3.1 discusses various approaches to modelling employer provision of private health insurance. The additional considerations when employees pay all or part the premium out of their pre-tax income, thus also facing a choice at the individual level, are accounted for in section 3.2.

\subsection{The decision of employers to offer duplicate private health insurance}

Employer behaviour as regards the provision of health insurance is surprisingly little explored in economics, and the theoretical literature is characterised by several different angles of approaches rather than a unified approach (Currie and Madrian, 1999). Regardless which theoretical approach is taken, employers may have a cost advantage over private individuals in the provision of health insurance given that group purchase has the potential to reduce adverse selection and lower administrative expenses through pooling (Gruber, 2000). The benefits from risk pooling imply that larger companies are expected to be relatively more likely to offer EPHI. In addition, the preferential tax treatment of EPHI which is found in some countries, including Denmark, may distort the preferences for the composition of the compensation package in favour of EPHI.

The employers' decision to offer EPHI may be analysed within the theoretical framework of compensating wage differentials for fringe benefit provision (Currie and Madrian, 1999). This framework considers EPHI as part of the total compensation package, which may be used by companies to attract and retain labour. Within this framework, firms are assumed to minimise their total labour costs, subject to maintaining the employees' utility at the level required to keep the firm competitive in the labour

\footnotetext{
${ }^{7}$ The value of EPHI makes up less than 0.5 percent of the average money wages for the permanently employed in Denmark (Statistics Denmark, 2009b; The Danish Insurance Association, 2010).
} 
market (Feldman et al., 1997). Hence, the employers' decision to offer health insurance depends on the price at which they can purchase it in the market and the preferences of current as well as potential employees.

Another approach to modelling employer provision of EPHI is to assume that the decision is made by aggregating employee preferences, either within firms or through union bargaining (Goldstein and Pauly, 1976). A common critique of this approach is that it is debatable how closely the mechanism used to determine the employers' provision of PHI resembles actual decision making processes within companies. In particular, the assumption that unions arbitrarily decide on the employers' provision of PHI has been argued to be unrealistic.

Considering the employers' demand for EPHI in a similar way as the individual demand, it may be argued that employers demand duplicate EPHI in order to protect themselves against the risk imposed by sickness absence, assuming that people get back to work quicker with EPHI. One implication of this is that companies using more specialised labour, which is usually highly paid and hard to replace in the case of illness, are more likely to invest in the health of their employees by taking out duplicate EPHI, again assuming that EPHI reduces sickness absence. Along a similar line, Grepperud and Iversen (2011) argued that provided that premiums are not risk rated, companies with a large share of employees in bad health and those operating in industries exposed to considerable health risks may be relatively more inclined to purchase EPHI, i.e. adverse selection at the company level.

Finally, Bolin et al. (2002) extended the health capital approach of Grossman (1972) to include employers and found that they may also have an interest in investing in the health of their employees, given that employees who are off work sick are costly in terms of sickness benefits and lost labour. The marginal benefit of an investment in health is shown to depend on the technology used in the employer's production, i.e. whether it is labour or capital intensive, as well as government regulation. Moreover, in an uncertain world, risk averse employers are predicted to make larger investments in the health of their employees (e.g. by providing EPHI) than they would in a perfectly certain world.

\subsection{The employees' demand for duplicate private health insurance}

In situations where employees are facing an actual choice, several factors may affect the decision to accept an offer of EPHI. For one thing, the demand for private health insurance has been shown to increase with the degree of risk aversion under symmetric information (Cutler and Zeckhauser, 2000). When asymmetric information is present, economic theory predicts that individuals may select themselves into private health insurance, either adversely based on their probability of falling ill (Rothschild and Stiglitz, 1976) or advantageously based on their probability of falling ill and their risk preferences (de Meza and Webb, 2001; Hemenway, 1990). The finding of adverse selection has been replicated for private health insurance that exists alongside a universal health care system by Olivella and Vera-Hernández (2006). However, the potential for selection at the individual level is reduced considerably for group based policies, and in regulatory settings such as the Danish, where EPHI is usually offered to all employees in a company or members of a trade union and premiums are tax-exempted.

Theoretical contributions that specifically modelled the demand for duplicate coverage have shown that individuals select themselves into this type of insurance by income (Besley et al., 1999), and emphasized the importance of the geographical accessibility of private facilities and the relative quality of care delivered by the taxfinanced and the private health care sectors, respectively (Propper et al., 2001). The 
selection on income implies that if employers take into account the preferences of their employees in deciding whether to offer EPHI, companies with highly paid employees will be more likely to include duplicate EPHI in the compensation package.

Another motive for taking out private health insurance is in order to gain access to health care that would otherwise be unaffordable (Nyman, 1999). In universal health care systems where treatment is typical free at the point of demand and hence there is no financial loss associated with illness, the access motive may be interpreted as gaining quick access to treatment (Jones et al., 2006).

\section{Previous empirical findings}

This section is restricted to consider studies of the determinants of EPHI in institutional settings that are somewhat similar to the Danish in the sense that EPHI duplicates the coverage provided by a universal health care system. The data, particular focus, and econometric methods of the reviewed studies are accounted for in Appendix A.

Empirical evidence on the employers' decision to take out duplicate EPHI on behalf of their employees in universal health care systems is sparse; only one study based on company-level data from Norway was identified. This study by Seim et al. (2007) found the probability of companies purchasing EPHI to some or all of their employees to be increasing with company size and profit, the share of younger employees, the education level of the staff of employees, and operating in industries exposed to considerable health risks (such as building and construction, farming, forestry, and mining).

The predominant part of the empirical literature is based on individual-level data, and the analyses were in all cases restricted to the populations of occupationally active individuals. Overall, it is noted that the majority of the empirical literature is based on a rather sparse theoretical framework. The findings of the various studies are accounted for by area as follows: 1) Sociodemographic characteristics, 2) health, 3) interactions with the state of the universal health care system, and 4) tax incentives.

Considering first the importance of sociodemographic determinants, the probability of EPHI ownership has consistently been found to increase with income. Likewise, males are generally found to be more likely to have EPHI than females (Aarbu, 2010; Besley et al., 1999; Bræmer, 2008; Grepperud and Iversen, 2011; King and Mossialos, 2005). The effect of age on the probability of having EPHI has been found to be positive until a given point and negative or insignificant thereafter in the United Kingdom and parts of it (Besley et al., 1999; King and Mossialos, 2005) and negative in Norway (Aarbu, 2010; Grepperud and Iversen, 2011). ${ }^{8}$ For education level, the empirical evidence is mixed. Studies from the United Kingdom found a positive association between education level and the probability of having EPHI (Besley et al., 1999; King and Mossialos, 2005). Likewise, descriptive evidence from Denmark indicated that the privately insured a better educated (Bræmer, 2008). On the contrary, Aarbu (2010) and Grepperud and Iversen (2011) found a negative association between higher education and EPHI coverage in Norway. However, additional analysis of the Norwegian data by Grepperud and Iversen (2011) revealed that the negative effect of education and the positive effect of being male lost their significance when dummies for sector of employment were included as explanatory variables. Regarding the importance of occupation, self-employed and public employees were generally found to be less likely to

\footnotetext{
${ }^{8}$ This individual-level finding from Norway corresponds well with the previously discussed company-level result of Seim et al. (2007) that companies with a larger share of younger employees are more likely to offer EPHI.
} 
be insured through their workplace, while the opposite applied to private sector employees, professionals, and individuals in managerial positions (Besley et al., 1999; Grepperud and Iversen, 2011; King and Mossialos, 2005). Finally, King and Mossialos (2005) found centre-right voters to be more likely to have EPHI in England.

The empirical evidence on the association between EPHI and health is ambiguous. Kjellberg et al. (2010) found that those in good or very good self-assessed health were relatively more likely to have EPHI in Denmark. On the contrary, dummy variables for good or very self-assessed health were largely insignificant in studies from England and Norway (Grepperud and Iversen, 2011; King and Mossialos, 2005), as was the presence of at least one chronic condition (Grepperud and Iversen, 2011). Moreover, Grepperud and Iversen (2011) found contacts with general practitioners and hospitalisations to be negatively and positively associated with the probability of having EPHI, respectively. The positive relationship between hospitalisations and EPHI ownership may be consistent with adverse selection into EPHI as well as moral hazard. Finally, King and Mossialos (2005) found a negative effect of smoking on the probability of having EPHI in England, while Aarbu (2010) found the opposite based on data from Norway.

Considering potential interactions between the state of the universal health care system and EPHI coverage, Besley et al. (1999) found the prevalence of private health insurance to be increasing with the regional long term waiting times for treatment at public hospitals in the United Kingdom, although the relationship was much weaker for EPHI than for individually purchased policies. Along a similar line, King and Mossialos (2005) found that regional outpatient waiting times and the supply of private surgeons were important determinants of EPHI ownership in England. Among the Scandinavian countries, Aarbu (2010) found no significant relationship between regional waiting lists and the prevalence of EPHI coverage in Norway.

Finally, Rodríguez and Stoyanova (2008) found that a shift in tax incentives which implicitly increased the price of individually purchased insurance and reduced the price of EPHI in Spain reduced the prevalence of the former and increased the prevalence of EPHI, as expected.

\section{Data}

The empirical analysis is based on a cross-sectional sample of the Danish population aged 18-75. This dataset contains the most detailed information on private health insurance coverage available to date. The data were collected in June 2009 using an internet-based questionnaire. The pilot-tested final questionnaire was e-mailed to a sample of 13,246 respondents via YouGov Zapera's Denmark panel. ${ }^{9}$ In total 5,447 respondents answered the questionnaire, which corresponds to a response rate of 41 percent. The sample is representative with respect to age, gender, and the region of residence, while individuals with only basic schooling or vocational training are somewhat underrepresented in the data.

The questionnaire and the data collection process, including further analyses of non-response and representativity, are fully documented in Kiil and Pedersen (2009). In

\footnotetext{
${ }^{9}$ YouGov Zapera's Denmark panel is an actively managed internet-based panel containing 38.600 members in Denmark as of July 2009. The YouGov Zapera Denmark panel meets the Esomar international code on marketing and social research practice. This implies among other things that its members are recruited through a wide selection of channels in order to ensure an appropriate demographic balance, and that panel members must $\log$ on with a password when participating in surveys in order to ensure that the intended person completes the survey (YouGov Zapera Ltd., 2009).
} 
the following, the variables measuring private health insurance coverage are described in detail in section 5.1, the selection of explanatory variables and their expected associations with EPHI coverage are accounted for in section 5.2, and section 5.3 presents some descriptive evidence for the explanatory variables by EPHI status.

\subsection{Private health insurance coverage}

The questionnaire included a series of questions on private health insurance coverage. First, the respondents were briefly introduced to the concept of private health insurance. Employed respondents were asked whether they were covered by private health insurance through their employer; and those who answered affirmatively were asked whether the employer paid the entire premium. Married and cohabiting respondents were asked whether they had a private health insurance through their partner's employer. Finally, all respondents were asked whether they had taken out private health insurance elsewhere (not counting membership of 'denmark'). Individuals who do not know their insurance status are dropped from the data, reducing the sample size from 5,447 to 5,031 individuals.

Table 1 shows the distribution of the private health insurance supplied by commercial insurance companies in Denmark for the total sample and for the subsample of employed.

Table 1 Source of private health insurance coverage for the total sample of the Danish population aged 18-75 and the subsample of employed, 2009

\begin{tabular}{|c|c|c|c|c|}
\hline Source of coverage & \multicolumn{2}{|c|}{$\begin{array}{c}A l l^{a} \\
(n=5,031)\end{array}$} & \multicolumn{2}{|c|}{$\begin{array}{l}\text { Employed }^{a} \\
(n=3,206)\end{array}$} \\
\hline \multicolumn{5}{|c|}{ Privately insured through commercial insurance company } \\
\hline Individually purchased & $5.98 \%$ & $(n=301)$ & $6.86 \%$ & $(n=220)$ \\
\hline Through own employer $(E P H I)^{b}$ & $25.04 \%$ & $(n=1,260)$ & $38.15 \%$ & $(n=1,223)$ \\
\hline Through partner's employer & $5.29 \%$ & $(n=266)$ & $6.74 \%$ & $(n=216)$ \\
\hline Not insured & $66.96 \%$ & $(n=3,369)$ & $52.78 \%$ & $(n=1,692)$ \\
\hline
\end{tabular}

It is evident from Table 1 that the primary source of private health insurance coverage is through one's own employer. Moreover, the percentage with insurance coverage is seen to be higher for the occupationally active part of the population for all insurance types.

The sample is restricted to the subsample of occupationally active for the purpose of this study, because individuals outside the labour force do not have private health insurance through their workplace by definition. This reduces the sample size from 5,031 to 3,206 individuals. In addition, the 216 individuals with private health insurance through their partner's employer and the 220 individuals who have purchased private health insurance from a commercial insurance company on an individual basis are excluded from the primary analysis based on the following considerations. The individuals who are 
covered through their partner's employer are excluded because the characteristics of the employer offering the insurance are not identified in the data. Hence, the determinants of this type of private health insurance cannot be meaningfully estimated and interpreted. The individuals with individually purchased private health insurance are excluded because even though these policies largely cover the same as the employment-based policies, the decision process that leads to this type of private health insurance coverage can reasonably be expected to differ markedly from the decision process that leads to EPHI coverage. Moreover, the number of individuals with individually purchased private health insurance is still modest. ${ }^{10}$ The resulting dataset includes 2,813 individuals.

\subsection{Hypotheses}

This section identifies the potential determinants of EPHI coverage and forms some hypotheses based on the theoretical framework and previous empirical findings, taking into account the particular institutional features that are present in the Danish health care system. The drawing up of hypotheses is intended to guide the selection of explanatory variables from the information available in the data and provide some benchmark against which to discuss the results.

Table 2 provides an overview of the potential determinants and accounts for a priori expectations regarding their relationship with EPHI coverage.

As accounted for in section 3, the theoretical literature suggests that employerrelated characteristics are important determinants of EPHI coverage, given that the initial decision to take out private health insurance is initiated at the company-level. This study includes sector of employment, employer size, and whether the individual has any subordinates as potential determinants. ${ }^{11}$ The presence of subordinates is not expected to affect the probability of having EPHI in Denmark, given that the condition for the taxexemption discourages companies from offering private health insurance to management level employees only.

\footnotetext{
${ }^{10}$ An exploratory analysis of the determinants of having purchased private health insurance from a commercial insurance company on an individual basis revealed only very few statistically significant associations.

${ }^{11}$ Given the major importance of the employers in offering EPHI in the first place, it would be desirable to include more employer-related characteristics in the analysis, such as the average age, sickness absence, and education level of the staff of employees in the company in which an individual is employed, as well as the work environment, human resource policies, etc. However, this information is not available in the data, and it cannot be obtained from Statistics Denmark and linked due to the absence of social security numbers in the data.
} 
Table 2 Hypotheses for potential determinants

Variable

Employer-related characteristics

Sector of employment

Employer size

Subordinates

Sociodemographic characteristics

Male

Age

Personal pre-tax income per year

Education level

Occupation

Member of 'denmark'

Company health scheme

Capital region

Health-related characteristics

Self-assessed health

Chronic conditions

Attitudinal characteristics

Satisfaction with tax-financed system
Expected association with EPHI coverage

\author{
positive for private; negative for public \\ positive \\ insignificant
}

positive
positive until a given point then negative
positive
ambiguous
positive for white-collar
insignificant
ambiguous
positive

ambiguous

ambiguous

The hypotheses regarding the sociodemographic characteristics gender, age, income, and education level are derived from the existing empirical literature. As far as occupational status is concerned, the probability of having EPHI coverage is expected to be higher for white-collar workers than for skilled and unskilled blue-collar workers. This expectation is motivated by the Danish labour market legislation, according to which white-collar workers are entitled to full pay during sickness, while this is not a matter of course for employees who are paid on an hourly basis (as often applies to skilled and unskilled workers). As a consequence, companies with a large share of white-collar workers are facing a larger financial risk as regards to the sickness absence of their employees, and they may thus be expected to attach a greater value to EPHI, causing white-collar workers to be more likely to have EPHI. Finally, living in the capital region is expected to increase the probability of having EPHI due to a higher concentration of knowledge-intensive enterprises as well as private treatment facilities in this area compared to the rest of the country.

Membership of the non-profit mutual insurance company 'denmark' is not expected to affect the probability of having EPHI, given that these two insurance types perform fundamentally different functions in relation to the tax-financed health care system. As for company health schemes, which differ from EPHI in the sense that they treat work-induced injuries only and do not provide any type of elective surgery at private facilities, the expected association with EPHI is ambiguous. While the most likely relationship among the two fringe benefits is that both tend to be offered by the same employers, i.e. those who assign a high value to having healthy employees, it is also possible that employers choose to offer company health schemes instead of EPHI. 
A priori, the relationship between EPHI ownership and health (measured by self-assessed health status and a set of dummy variables indicating the presence of eight chronic conditions) is expected to be ambiguous, given the theoretical framework and the previous empirical findings accounted for in sections 3 and 4, respectively. Contacts to health care providers were not included as explanatory variables given that these variables may likely be affected by EPHI coverage and thus endogenous. Moreover, it was decided not to include various health-related behaviours, such as smoking, drinking, and exercising, as well as self-reported measures of attitude to economic and health-related risk in the model (even though the information was available in the data), since there are no compelling theoretical arguments or empirical evidence in favour of doing so. ${ }^{12}$

Finally, the link between the state of the tax-financed system and EPHI coverage is explored by including satisfaction with the tax-financed health care system as an explanatory variable. The association between the level of satisfaction and EPHI ownership is expected to be stronger for individuals who pay the premium out of their pretax income and thus make an actual choice than for those who receive EPHI free of charge. The reason for including satisfaction rather than information on regional waiting times or other quality measures is that the combination of free hospital choice for many elective procedures and low geographical distances in Denmark implies that any differences in waiting time for treatment between the regions should be levelled out.

\subsection{Descriptive evidence}

Table 3 shows how the characteristics of the individuals are distributed on the explanatory variables for all employed and by EPHI status, and tests for equality of proportions or means between individuals with and without EPHI, respectively. This allows for a first inspection of possible differences between the groups.

Respondents who answered 'don't know' or 'other' than the categories specified in the questionnaire to one or more of the explanatory variables are dropped from the data before commencing the analysis, reducing the sample size further from 2,813 to 2,536 individuals. ${ }^{13}$ The main motivation for this data restriction is that it is questionable whether the individuals in the 'don't know' and 'other' groups have anything in common. Moreover, the signs of potential marginal effects for these categories cannot meaningfully be interpreted. Due to a particularly large share of respondents who do not wish to disclose their personal pre-tax income, a dummy variable is included that equals one whenever respondents do not wish to disclose their income and zero otherwise. ${ }^{14}$

As evident from Table 3, the resulting dataset includes 2,536 individuals, of whom 42 percent are covered by private health insurance through their employer. Within the group of individuals with EPHI, 71 percent receives the insurance free of charge, 26 percent pays the premium themselves out of their pre-tax income, and 3 percent do not

\footnotetext{
${ }^{12}$ It was checked that including health-related behaviours and risk preferences as explanatory variables did not affect the results notably, and that the coefficients for these variables were largely insignificant. These results are available from the author upon request.

${ }^{13}$ The dropped individuals are distributed as follows: 6 did not know their sector of employment; 66 did not know the size of their workplace; 17 did not know their personal pre-tax income; 29 stated to work in a sector other than those specified in the questionnaire; 42 stated to have an education other than those specified in the questionnaire; and 123 individuals stated to have an occupation other than those specified in the questionnaire.

${ }^{14}$ An alternative strategy would be to impute all missing values.
} 
know how the premium is paid. In other words, the employer pays the entire premium for the majority of the insured.

Table 3 Distribution on explanatory variables for all employed and by EPHI status

\begin{tabular}{|c|c|c|c|c|}
\hline & $\begin{array}{c}\text { All } \\
\text { employed }\end{array}$ & EPHI & $\begin{array}{c}\text { No } \\
\text { EPHI }\end{array}$ & $\begin{array}{c}\text { Two-sided test } \\
\text { for equality } \\
\text { (EPHI vs. no } \\
\text { EPHI) }\end{array}$ \\
\hline & $\%$ & $\%$ & $\%$ & z-statistic \\
\hline \multicolumn{5}{|l|}{ Employer-related characteristics } \\
\hline \multicolumn{5}{|l|}{ Sector of employment } \\
\hline Public company & 36.24 & 6.49 & 57.71 & $-26.47 * * *$ \\
\hline Independent public company & 3.46 & 3.95 & 3.67 & 0.65 \\
\hline Private company & 60.09 & 89.56 & 38.83 & $25.74 * * *$ \\
\hline \multicolumn{5}{|l|}{ Employer size } \\
\hline 1-9 employees & 17.07 & 9.69 & 22.40 & $-8.40 * * *$ \\
\hline 10-49 employees & 27.76 & 25.68 & 29.26 & $-1.99 * *$ \\
\hline 50-249 employees & 27.13 & 28.03 & 26.48 & 0.87 \\
\hline $250+$ employees & 28.04 & 36.59 & 21.86 & $8.15 * * *$ \\
\hline Any subordinates & 21.92 & 23.24 & 20.98 & 1.36 \\
\hline \multicolumn{5}{|l|}{ Sociodemographic characteristics } \\
\hline Male & 53.12 & 57.67 & 49.83 & $3.90 * * *$ \\
\hline Age, mean & 45.07 & 43.82 & 45.98 & $-4.70 * * *$ \\
\hline \multicolumn{5}{|l|}{$\begin{array}{l}\text { Personal pre-tax income per year } \\
\text { (in 1,000s) }\end{array}$} \\
\hline DKK 0-399/EUR 0-54 & 55.09 & 44.31 & 62.86 & $-9.27 * * *$ \\
\hline DKK 400-799/EUR 54-107 & 34.03 & 42.90 & 27.63 & $8.01 * * *$ \\
\hline DKK 800+/EUR 107+ & 2.60 & 3.67 & 1.83 & $2.87 * * *$ \\
\hline Do not wish to disclose & 8.28 & 9.13 & 7.67 & 1.31 \\
\hline \multicolumn{5}{|l|}{ Education level } \\
\hline Basic or high school & 13.13 & 12.61 & 13.51 & -0.67 \\
\hline Vocational & 26.81 & 29.82 & 24.64 & $2.90 * * *$ \\
\hline College & 60.06 & 57.57 & 61.85 & $-2.17 * *$ \\
\hline \multicolumn{5}{|l|}{ Occupation } \\
\hline White-collar worker & 77.29 & 81.75 & 74.07 & $4.56 * * *$ \\
\hline Skilled worker & 7.06 & 7.43 & 6.79 & 0.62 \\
\hline Unskilled worker & 7.49 & 7.53 & 7.47 & 0.05 \\
\hline Self-employed or assisting spouse & 8.16 & 3.29 & 11.68 & $-7.61 * * *$ \\
\hline Member of 'denmark' & 54.89 & 56.16 & 53.97 & 1.09 \\
\hline Company health scheme & 28.94 & 41.86 & 19.62 & $12.17 * * *$ \\
\hline Capital region & 33.52 & 36.50 & 31.36 & $2.70 * * *$ \\
\hline
\end{tabular}

\section{Health-related characteristics}

Self-assessed health status

$\begin{array}{lcccc}\text { Excellent } & 16.68 & 15.80 & 17.31 & -1.00 \\ \text { Good } & 56.62 & 61.05 & 53.43 & 3.82 * * *\end{array}$




$\begin{array}{lllll}\text { Fair, poor or very poor } & 26.70 & 23.14 & 29.26 & -3.44^{* * *} \\ \text { Chronic conditions } & & & & \\ \text { Asthma } & 5.88 & 5.55 & 6.11 & -0.59 \\ \text { Allergies } & 23.90 & 25.59 & 22.67 & 1.70^{*} \\ \text { Diabetes } & 3.94 & 3.76 & 4.07 & -0.40 \\ \text { Hypertension } & 13.29 & 11.95 & 14.26 & -1.69^{*} \\ \text { Emphysema } & 1.81 & 1.69 & 1.90 & -0.39 \\ \text { Arthritis } & 13.56 & 10.63 & 15.68 & -3.67^{* * *} \\ \text { Osteoporosis } & 1.10 & 0.85 & 1.29 & -1.05 \\ \text { Tinnitus } & 7.93 & 7.06 & 8.55 & -1.38\end{array}$

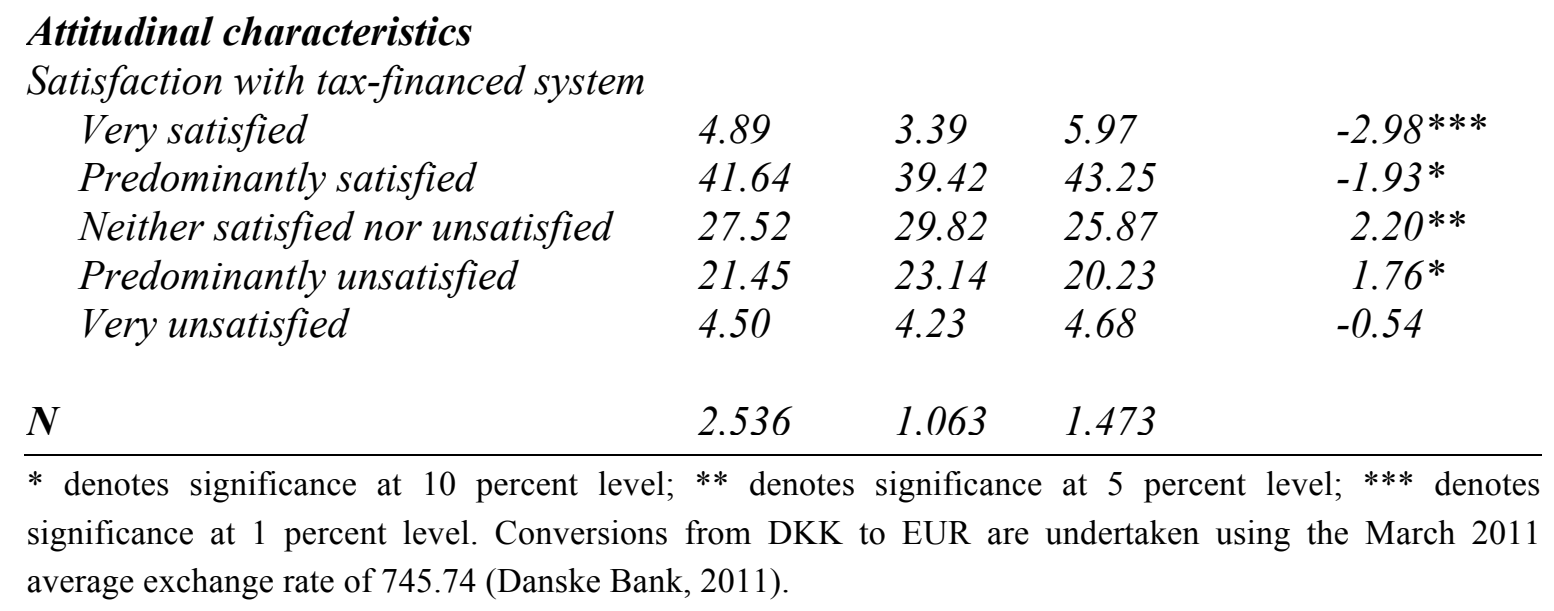

The expectations that EPHI is mainly a private sector phenomenon and that it is more frequently offered in larger companies are confirmed by Table 3. Likewise for the sociodemographic characteristics, where the differences in the distributions between the group with EPHI and the group without are by and large as expected. One exception to this is education, where it is seen that EPHI is relatively more frequent in the group of vocationally trained, while the opposite applies to the group of individuals with at least college level education. Members of 'denmark' are equally distributed in the two groups. Considering self-assessed health, individuals with EPHI are overrepresented in the group with good self assessed health and reversely for the remaining categories, although the difference is not significant for the individuals in excellent health. Except for arthritis, the prevalence of the chronic conditions does not differ significantly between the two groups. As expected, Table 3 reveals a pattern of relatively more individuals who are satisfied with the tax-financed health care system in the group without EPHI and the other way around for the group with EPHI coverage, although the percentage of very unsatisfied individuals does not differ significantly.

\section{Econometric specification}

The determinants of having EPHI altogether, either fully paid by the employer or deducted from the pre-tax income of the employee, are estimated using a standard binary probit model. This model compares the total group of individuals with EPHI to the group of individuals without EPHI.

Taking into account that some employees receive EPHI free of charge, while others pay the premium out of their pre-tax income and thus make an actual choice, the econometric specification becomes less straight forward. One way to address this complication is by estimating a bivariate probit model with sample selection (Greene, 
1999; Van de Ven et al., 1981). ${ }^{15}$ This model is somewhat in between a full bivariate probit model and a bivariate probit model with partial observability, in the sense that we observe more than in the partial observability model but less than in the full bivariate probit model. ${ }^{16}$

The econometric specification consists of two simultaneous equations:

$$
\begin{aligned}
& y_{1 i}^{*}=X_{1 i} \beta_{1}+\varepsilon_{1 i} \\
& y_{2 i}^{*}=X_{2 i} \beta_{2}+\varepsilon_{2 i}
\end{aligned} \quad \text {, for } i=1, \ldots, N
$$

where $y_{1 i}^{*}$ and $y_{2 i}^{*}$ are unobserved latent variables indicating an individual's propensity to have EPHI and to have paid the premium, respectively; $X_{1 i}$ and $X_{2 i}$ denote the vectors of explanatory variables, where the first variable in each vector is set to unity; $\beta_{1}$ and $\beta_{2}$ are the two vectors of parameters to be estimated; and $\varepsilon_{1 i}$ and $\varepsilon_{2 i}$ are the random error terms, which are assumed to follow a standard bivariate normal distribution with correlation coefficient $\rho$. Assuming that the model is correctly specified, $\rho \neq 0$ implies that the processes determining $y_{1 i}^{*}$ and $y_{2 i}^{*}$ are interdependent. In the special case where $\rho=0$, the bivariate probit model with sample selection is equivalent to estimating two separate probit models (although of course for the latter model on a restricted subsample). The latent variables, $y_{1 i}^{*}$ and $y_{2 i}^{*}$, are measured by the two binary variables, $y_{1 i}$ and $y_{2 i}$, which are generated by the following rule:

$$
y_{1 i}=\left\{\begin{array}{l}
1 \quad \text { if } y_{1 i}^{*}>0 \\
0 \quad \text { if } y_{1 i}^{*}=0
\end{array} \quad y_{2 i}= \begin{cases}1 & \text { if } y_{2 i}^{*}>0 \\
0 & \text { if } y_{2 i}^{*}=0\end{cases}\right.
$$

The first equation identifies whether the respondent has EPHI, $y_{1 i}$, and the second equation identifies whether the respondent has paid the premium for the EPHI out if its pre-tax income, $y_{2 i}$, conditional on having EPHI. Selection occurs because for a given individual $y_{2 i}$ is only observed when $y_{1 i}$ equals one. In other words, it is only observed whether the individual pays the premium or receives the insurance for free for the subsample of insured. For the uninsured, it is not known whether they would have had to pay the premium themselves, had they been insured.

Thus, there are three types of observations in the sample with the following probabilities:
$y_{1 i}=1, y_{2 i}=1$
$\operatorname{Pr}\left(y_{1 i}=1, y_{2 i}=1\right)=\Phi_{2}\left(X_{1 i} \beta_{1 i}, X_{2 i} \beta_{2 i}, \rho\right)$
$y_{1 i}=1, y_{2 i}=0$
$\operatorname{Pr}\left(y_{1 i}=1, y_{2 i}=0\right)=\Phi_{2}\left(X_{1 i} \beta_{1 i},-X_{2 i} \beta_{2 i},-\rho\right)$
(3)
$y_{1 i}=0$
$\operatorname{Pr}\left(y_{1 i}=0\right)=1-\Phi\left(X_{1 i} \beta_{1 i}\right)$

\footnotetext{
${ }^{15}$ This approach is preferred over estimating two separate probit models (i.e. one for employees who receive EPHI free of charge and one for those who pay the premium out of their pre-tax income) given that the error terms of two such equations may be correlated.

${ }^{16}$ Previous applications of this model include among others Berinsky (2004) who examined attitudes towards race issues in the US and Rodríguez and Stoyanova (2008) who estimated the impact of a tax reform on the demand for private health insurance in Spain. The presentation of the bivariate probit model with sample selection in this section follows that of Rodríguez and Stoyanova (2008).
} 
where $\Phi$ and $\Phi_{2}$ are the univariate and the bivariate standard normal cumulative distribution functions, respectively. The first line in equation system (3) models individuals who are insured through their employer but pay the premium out of their pretax income and thus make an actual choice, the second line models individuals who are insured free of charge through their employer, and the third line models individuals who do not have any type of private health insurance through their workplace.

The log-likelihood function based on these probabilities is:

(4)

$$
\begin{aligned}
& \log L=\sum_{\substack{y_{1 i}=1 \\
y_{2 i}=1}} \log \Phi_{2}\left(X_{1 i} \beta_{1}, X_{2 i} \beta_{2}, \rho\right)+\sum_{\substack{y_{1 i}=1 \\
y_{2 i}=0}} \log \Phi_{2}\left(X_{1 i} \beta_{1},-X_{2 i}, \beta_{2},-\rho\right) \\
& +\sum_{y_{1 i}=0} \log \left(1-\Phi\left(X_{1 i} \beta_{1}\right)\right)
\end{aligned}
$$

The log-likelihood function is maximised with respect to the two vectors of coefficients, $\beta_{1}$ and $\beta_{2}$, and the correlation coefficient $\rho$.

As in several other models involving multiple equations, the magnitude and the signs of the simple coefficients in the bivariate probit model with sample selection can be misleading. Hence, marginal effects are calculated at the means of the explanatory variables in accordance with Greene (1996). For continuous variables, the marginal effects are given by the derivatives of the probabilities stated in (3) with respect to the explanatory variable of interest. For binary variables, they are computed as the effect of changing the variable from zero to one, holding all other variables constant.

The bivariate probit model with sample selection is identified through functional form. However, it is preferable to include one or more variables that affect the probability of having EPHI, but not whether this is received free of charge or paid for, when such variables are available in the data.

\section{Results}

Stata/IC 11 was used to estimate the models and compute marginal effects and standard errors. Table 4 reports the results of the binary probit model which analyses the determinants of having EPHI altogether, i.e. either fully paid by the employer or deducted from the pre-tax income. 
Table 4 Marginal effects from binary probit model

\begin{tabular}{|c|c|c|c|}
\hline & \multicolumn{2}{|c|}{$\begin{aligned} & y_{i}= 1 \text { for individuals } \\
& \text { with EPHI }\end{aligned}$} & \multirow[t]{2}{*}{ Expected sign } \\
\hline & Marg. eff. & Std. err. & \\
\hline \multicolumn{4}{|l|}{ Employer-related characteristics } \\
\hline \multicolumn{4}{|l|}{ Sector of employment } \\
\hline Public company (baseline) & $n / a$ & $n / a$. & \\
\hline Independent public company & $0.4615 * * *$ & $(0.0435)$ & + \\
\hline Private company & $0.6422 * * *$ & $(0.0164)$ & + \\
\hline \multicolumn{4}{|l|}{ Employer size } \\
\hline 1-9 employees (baseline) & $n / a$ & $n / a$ & \\
\hline 10-49 employees & $0.1951 * * *$ & $(0.0408)$ & + \\
\hline 50-249 employees & $0.2598 * * *$ & $(0.0421)$ & + \\
\hline $250+$ employees & $0.3405 * * *$ & $(0.0415)$ & + \\
\hline Any subordinates & 0.0133 & $(0.0304)$ & insig. \\
\hline \multicolumn{4}{|l|}{ Sociodemographic characteristics } \\
\hline Male & 0.0266 & $(0.0259)$ & + \\
\hline Age & $0.0297 * * *$ & $(0.0079)$ & + \\
\hline $\mathrm{Age}^{2}$ & $-0.0003 * * *$ & $(0.0001)$ & - \\
\hline \multicolumn{4}{|l|}{ Personal income (in 1,000s) } \\
\hline DKK 0-399/EUR 0-54 & $-0.0490^{*}$ & $(0.0294)$ & - \\
\hline DKK 400-799/EUR 54-107 (baseline) & $n / a$ & $n / a$ & \\
\hline DKK $800+/ E U R 107+$ & $0.1615^{* *}$ & $(0.0811)$ & + \\
\hline Do not wish to disclose & -0.0007 & $(0.0467)$ & insig. \\
\hline \multicolumn{4}{|l|}{ Education level } \\
\hline Basic or high school (baseline) & $n / a$ & $n / a$ & \\
\hline Vocational & 0.0415 & $(0.0412)$ & ambig. \\
\hline College & 0.0543 & $(0.0374)$ & ambig. \\
\hline \multicolumn{4}{|l|}{ Occupation } \\
\hline White-collar worker (baseline) & $n / a$ & $n / a$ & \\
\hline Skilled worker & $-0.0962 * *$ & $(0.0412)$ & - \\
\hline Unskilled worker & $-0.1028 * *$ & $(0.0406)$ & - \\
\hline Self-employed or assisting spouse & $-0.2928 * * *$ & $(0.0281)$ & - \\
\hline Member of 'denmark' & 0.0333 & $(0.0238)$ & insig. \\
\hline Company health scheme & $0.2540^{* * *}$ & $(0.0270)$ & ambig. \\
\hline Capital region & 0.0361 & $(0.0255)$ & + \\
\hline \multicolumn{4}{|l|}{ Health-related characteristics } \\
\hline \multicolumn{4}{|l|}{ Self-assessed health status } \\
\hline Excellent & $-0.0774 * *$ & $(0.0306)$ & ambig. \\
\hline Good (baseline) & $n / a$ & $n / a$ & \\
\hline Fair, poor or very poor & $-0.0768 * * *$ & $(0.0282)$ & ambig. \\
\hline \multicolumn{4}{|l|}{ Chronic conditions } \\
\hline Asthma & -0.0158 & $(0.0523)$ & ambig. \\
\hline Allergies & 0.0379 & $(0.0293)$ & ambig. \\
\hline Diabetes & 0.0512 & $(0.0664)$ & ambig. \\
\hline
\end{tabular}




$\begin{array}{lccc}\text { Hypertension } & 0.0031 & (0.0383) & \text { ambig. } \\ \text { Emphysema } & 0.0165 & (0.0887) & \text { ambig. } \\ \text { Arthritis } & -0.0853 * * & (0.0347) & \text { ambig. } \\ \text { Osteoporosis } & 0.0301 & (0.1216) & \text { ambig. } \\ \text { Tinnitus } & -0.0639 & (0.0413) & \text { ambig. }\end{array}$

\section{Attitudinal characteristics}

Satisfaction with tax-financed system

Very satisfied (baseline)

Predominantly satisfied

Neither satisfied nor unsatisfied

Predominantly unsatisfied

Very unsatisfied

$\begin{array}{lcc}n / a & n / a & \\ 0.1071 * & (0.0613) & + \\ 0.1178 * & (0.0643) & + \\ 0.1417 * * & (0.0662) & + \\ 0.2380 * * * & (0.0846) & +\end{array}$

N

2,536

Log-likelihood

$-1,060.04$

$\operatorname{LR} \chi^{2}(d f=34)$

$1,328.99 * * *$

* denotes significance at 10 percent level; ** denotes significance at 5 percent level; *** denotes significance at 1 percent level. $\mathrm{n} / \mathrm{a}$ is used to denote not applicable. Conversions from DKK to EUR are undertaken using the March 2011 average exchange rate of 745.74 (Danske Bank, 2011).

As expected, the characteristics related to the workplace are by far the quantitatively most important determinants of whether or not one has EPHI, except for the presence of subordinates, which is insignificant. Compared to public employees, those working at independent public companies are 46.15 percentage points more likely to have EPHI and private employees are 64.22 percentage points more likely. Likewise, the association between employer size and the probability of having EPHI is positive as expected.

Considering the sociodemographic characteristics, the association between age and the probability of having EPHI is seen to change at different points in the distribution of age. In particular, an additional year of age increases the probability of having EPHI by 2.97 percentage points until the age of 49, whereafter EPHI prevalence decreases with age. Individuals with an annual pre-tax income of DKK 800,000 or more are 16.15 percentage points more likely to have EPHI compared to individuals in the middle group with annual incomes of DKK 400,000-799,999, while those who earn less than DKK 400,000 are 4.90 percentage points less likely. Compared to white-collar workers, skilled and unskilled workers are 9.62 and 10.28 percentage points, respectively, less likely to have EPHI, and self-employed or assisting spouses are 29.28 percentage points less likely. Working for a company with a health scheme increases the probability of having EPHI by 25.40 percentage points.

Considering next the association between EPHI status and health, individuals in excellent self-assessed health are seen to be 7.74 percentage points less likely to be covered by EPHI compared to those in good self-assessed health, and individuals in fair, poor or very poor health are 7.68 percentage points less likely. The dummy variables indicating the presence of eight chronic conditions are all insignificant except for arthritis, which is found to decrease the probability of having EPHI by 8.53 percentage points.

Finally, it is seen from Table 4 that compared to the group of individuals who are very satisfied with the tax-financed health care system, individuals who are predominantly unsatisfied are 14.17 percentage points more likely to have EPHI and those who are very unsatisfied are 23.80 percentage points more likely. This confirms the hypothesis that the 
demand for EPHI that covers treatment at private facilities for treatments which are also available within the universal tax-financed health care system is somehow related to the perception of the public alternative.

Table 5 reports the results of the bivariate probit model with sample selection. This model takes into account that some employees receive the insurance free of charge while others pay the premium out of their pre-tax income by modelling the probability of having EPHI altogether and the probability that it is paid for and thus resulting from an actual choice simultaneously. The 32 individuals who do not know who paid the premium for their EPHI are excluded from the analysis.

Table 5 Marginal effects from bivariate probit model with sample selection

\begin{tabular}{|c|c|c|c|c|}
\hline & \multicolumn{2}{|c|}{$\begin{aligned} & y_{1 i}= 1 \text { for individuals } \\
& \text { with } E P H I\end{aligned}$} & \multicolumn{2}{|c|}{$\begin{array}{l}y_{2 i}=1 \text { for individu } \\
\text { who pay the premiu }\end{array}$} \\
\hline & Marg. eff. & Std. err. & Marg. eff. & Std. err. \\
\hline \multicolumn{5}{|l|}{ Employer-related characteristics } \\
\hline \multicolumn{5}{|l|}{ Sector of employment } \\
\hline Public company (baseline) & $n / a$ & $n / a$ & $n / a$ & $n / a$ \\
\hline Independent public company & $0.4592 * * *$ & $(0.0462)$ & -0.1001 & $(0.2758)$ \\
\hline Private company & $0.6389 * * *$ & $(0.0162)$ & -0.2208 & $(0.3774)$ \\
\hline \multicolumn{5}{|l|}{ Employer size } \\
\hline 1-9 employees (baseline) & $n / a$ & $n / a$ & $n / a$ & $n / a$ \\
\hline 10-49 employees & $0.1889 * * *$ & $(0.0410)$ & 0.0375 & $(0.1270)$ \\
\hline 50-249 employees & $0.2586^{* * *}$ & $(0.0424)$ & 0.2229 & $(0.1809)$ \\
\hline $250+$ employees & $0.3397 * * *$ & $(0.0420)$ & 0.1728 & $(0.1982)$ \\
\hline Any subordinates & 0.0234 & $(0.0304)$ & 0.0440 & $(0.0447)$ \\
\hline \multicolumn{5}{|l|}{ Sociodemographic characteristics } \\
\hline Male & 0.0229 & $(0.0259)$ & 0.0163 & $(0.0374)$ \\
\hline Age & $0.0291 * * *$ & $(0.0078)$ & -0.0086 & $(0.0163)$ \\
\hline $\mathrm{Age}^{2}$ & $-0.0003 * * *$ & $(0.0001)$ & 0.0001 & $(0.0002)$ \\
\hline \multicolumn{5}{|l|}{ Personal income (in 1,000s) } \\
\hline DKK 0-399/EUR 0-54 & $-0.0622 *$ & $(0.0294)$ & 0.0499 & $(0.0452)$ \\
\hline $\begin{array}{c}\text { DKK 400-799/EUR 54-107 } \\
\text { (baseline) }\end{array}$ & $n / a$ & $n / a$ & $n / a$ & $n / a$ \\
\hline DKK 800+/EUR 107+ & 0.1517 & $(0.0823)$ & -0.0373 & $(0.1027)$ \\
\hline Do not wish to disclose & -0.0135 & $(0.0467)$ & 0.0295 & $(0.0603)$ \\
\hline \multicolumn{5}{|l|}{ Education level } \\
\hline Basic or high school (baseline) & $n / a$ & $n / a$ & $n / a$ & $n / a$ \\
\hline Vocational & 0.0487 & $(0.0411)$ & 0.0306 & $(0.0628)$ \\
\hline College & 0.0482 & $(0.0371)$ & 0.0032 & $(0.0579)$ \\
\hline \multicolumn{5}{|l|}{ Occupation } \\
\hline White-collar worker (baseline) & $n / a$ & $n / a$ & $n / a$ & $n / a$ \\
\hline Skilled worker & $-0.0942 *$ & $(0.0408)$ & 0.0844 & $(0.0698)$ \\
\hline Unskilled worker & $-0.0974^{*}$ & $(0.0400)$ & 0.0971 & $(0.0744)$ \\
\hline \multicolumn{5}{|l|}{ Self-employed or } \\
\hline assisting spouse & $-0.2856^{* * *}$ & $(0.0272)$ & 0.1548 & $(0.1804)$ \\
\hline Member of 'denmark' & 0.0342 & $(0.0238)$ & 0.0259 & $(0.0366)$ \\
\hline Company health scheme & $0.2513 * * *$ & $(0.0274)$ & -0.0837 & $(0.0942)$ \\
\hline
\end{tabular}


Capital region

0.0248

(0.0256)

$-0.0464$

(0.0358)

Health-related characteristics

Self-assessed health status

$\begin{array}{lccrc}\text { Excellent } & -0.0748^{*} & (0.0305) & 0.0825 & (0.0501) \\ \text { Good (baseline) } & n / a & n / a & n / a & n / a \\ \text { Fair, poor or very poor } & -0.0667^{*} & (0.0281) & 0.0200 & (0.0484) \\ \text { Chronic conditions } & & & & \\ \text { Asthma } & -0.0183 & (0.0527) & -0.0193 & (0.0788) \\ \text { Allergies } & 0.0382 & (0.0293) & -0.0255 & (0.0419) \\ \text { Diabetes } & 0.0558 & (0.0661) & -0.0407 & (0.0928) \\ \text { Hypertension } & 0.0098 & (0.0389) & -0.0390 & (0.0555) \\ \text { Emphysema } & 0.0149 & (0.0879) & -0.1898 & (0.1355) \\ \text { Arthritis } & -0.0862^{*} & (0.0342) & 0.0137 & (0.0656) \\ \text { Osteoporosis } & 0.0227 & (0.1203) & -0.1931 & (0.1797) \\ \text { Tinnitus } & -0.0820^{*} & (0.0409) & 0.0142 & (0.0723)\end{array}$

\section{Attitudinal characteristics}

Satisfaction with tax-financed system

Very satisfied (baseline)

Predominantly satisfied

$\begin{array}{lcrc}\quad n / a & n / a & n / a & n / a \\ 0.1050 & (0.0612) & -0.0228 & (0.0987) \\ & & & \\ 0.1082 & (0.0644) & -0.0206 & (0.0996) \\ 0.1391^{*} & (0.0665) & -0.0095 & (0.1079) \\ 0.2448^{* *} & (0.0857) & 0.0530 & (0.1502)\end{array}$

Neither satisfied nor

unsatisfied

Predominantly unsatisfied

Very unsatisfied

$-0.5075$

(0.5582)

Correlation of error terms $(\rho)$

$N$

2,500

\section{Log-likelihood}

$-1,599.23$

Wald $\chi^{2}(d f=34)$

$56.89 * * *$

* denotes significance at 10 percent level; ** denotes significance at 5 percent level; *** denotes significance at 1 percent level. $\mathrm{n} / \mathrm{a}$ is used to denote not applicable. Conversions from DKK to EUR are undertaken using the March 2011 average exchange rate of 745.74 (Danske Bank, 2011).

It is seen from Table 5 that none of the marginal effects of the various explanatory variables on the probability of having EPHI which is paid for out of the pre-tax income $\left(y_{2 i}\right)$ differ significantly from zero. Hence, the determinants of having EPHI which is paid for out of the pre-tax income do not differ significantly from the determinants of having EPHI altogether (i.e. either fully paid by the employer or deducted from the pre-tax income). In addition, the marginal effects of the various explanatory variables on the probability of having EPHI altogether are largely similar to those obtained by a binary probit model, besides from a slight drop in the level of significance for some variables (high income, skilled and unskilled worker, self-assessed health status, arthritis, and the level of satisfaction with the tax-financed system). The bivariate probit model with sample 
selection for which results are reported in Table 5 is only identified through functional form because no suitable exclusion restrictions were identified in the data. ${ }^{17}$

\section{Discussion}

Like all studies, this study is subject to some methodological considerations regarding the data and econometric specifications. These are discussed in sections 8.1 and 8.2, respectively. Section 8.3 discusses possible interpretations and implications of the results and holds them against previous empirical findings.

\subsection{Data}

The use of data collected using an internet-based questionnaire constitutes a source of bias if the individuals who can be reached through the internet differ from those without internet access on the characteristics that are subject to investigation. This is, however, not expected to be a major issue in the present study, given that 86 percent of the Danish population had internet access in their homes in 2009 (Statistics Denmark, 2009a). In addition, the percentage with internet access is most likely higher among the occupationally active, to whom the analysis is restricted. Along a similar line, the identification of respondents through YouGov Zapera's Denmark panel constitutes a weakness of the study if the panel members differ from the remaining population on the relevant characteristics. ${ }^{18}$ While none of these data issues can be dismissed with complete certainty, it is, however, worth noting that there are no indications that the sample deviates considerably from the population on essential characteristics besides from individuals with only basic schooling or vocational training being somewhat underrepresented (Kiil and Pedersen, 2009).

Although it is in line with what is commonly seen in internet-based surveys (Cook et al. 2000; Sheehan 2006), the response rate of 41 percent is not impressive and may be argued to hamper the ability to make inferences about the study population. However, the extent of bias entailed by a low response rate is a function of the response rate itself as well as differences between respondents and non-respondents on the variables of interest. In the present study, it is possible that the respondents differ from those who did not answer the questionnaire by having a greater interest in the subject of the survey, i.e.

\footnotetext{
${ }^{17}$ The various sociodemographic, health-related, and attitudinal characteristics are disregarded because they may reasonably be expected to affect the probability of having EPHI which is paid out of the pre-tax income through the mechanisms discussed in section 3.2. This leaves the employer-related characteristics. Excluding sector of employment from the second equations brings about a slight change in the results such that the size of the workplace increases the probability of having paid the premium. However, sector of employment is most likely not a valid exclusion restriction given that the share of individuals who are required to pay the EPHI out of their pre-tax income is considerably higher in the public sector compared to what is expected for private companies (Kjellberg et al., 2010). Excluding the size of the workplace from the second equation changes the results slightly such that being self-employed and employed in the public sector is found to increase the probability of having EPHI which is paid for out of the pre-tax income at a 5 percent level of significance.

${ }^{18}$ An additional, although somewhat hypothetical, issue with the identification of respondents through web panels is that when it is possible to enrol in the panel on a voluntary basis, the established principles of statistical inference are in theory not applicable. These are only applicable to probability based samples where all members of the population have known and positive probabilities of selection (Couper, 2000). However, the practical importance of some extent of voluntary enrolment in web panels has yet to be assessed.
} 
private health insurance. Such an interest could be spurred by being strongly for or against private health insurance, and it may be positively or negatively related to health. Moreover, it is uncertain how this relates to the remaining variables used in this study. Hence, while caution should always be exercised when generalising results based on survey data to populations, there are no obvious reasons to believe that the results of this study are systematically biased by non-response.

\subsection{Econometric specification}

Considering the decision process that leads to EPHI coverage, i.e. the supply of private health insurance by the commercial insurance companies, the decision of employers to offer EPHI, and the decision of the employees to accept or reject this offer when this is relevant, it appears that the ideal econometric specification would be a multilevel model. This approach would enable a separation of the effects of the determinants on the various participants in the decision process. It is, however, not possible given the data at hand.

Both the binary probit model and the bivariate probit model with sample selection estimated in this study are reduced form models in the sense that they estimate the determinants of EPHI coverage net of demand- and supply-side effects. This imposes some limitations on the ability to identify causal relationships, and it does not allow for the estimation of how specific factors impact either side of the market. More precisely, it is not possible to separate the effects of the determinants on the various participants in the decision process that leads to EPHI coverage. Attempting to identify the demand and supply functions separately and estimate the full structural model would require one to find exogenous variables that relate exclusively to either demand or supply (Maddala, 2001). Such variables are notoriously hard to find in private health insurance markets, where most factors tend to affect supply and demand simultaneously (King and Mossialos, 2005).

\subsection{Results}

Due to the finding of the bivariate probit model that the determinants of EPHI which is paid for out of the pre-tax income of the employee do not differ significantly from the determinants of having EPHI altogether, the determinants of EPHI coverage are discussed jointly for individuals who receive fully employer paid EPHI and those who have the premium deducted from their pre-tax income in the following.

As expected, the probability of having EPHI increases substantially with private sector employment and the size of the workplace. The finding that private sector employees are more likely to be insured through their workplace corresponds well with the previous literature (Besley et al., 1999; Grepperud and Iversen, 2011; King and Mossialos, 2005) and the fact that fringe benefits are generally more predominant in the private sector in Denmark. In addition to that, it may be argued that it would seem somewhat paradoxical if employees at public hospitals are given insurance that covers elective surgery at private facilities as part of their pay. The positive effect of employer size is likely to reflect the fact that larger companies generally pay less per employee covered because the scope for risk pooling increases with company size. The positive association between EPHI ownership and working for an employer with a company health scheme in place suggests that both benefits are offered by employers who focus on the health of their employees and play an active part in promoting this.

The lack of an effect of whether the individual has any subordinates suggests that it is not common practice within Danish companies to offer EPHI exclusively to highly ranked employees, as opposed to what was found to be the case in the United Kingdom 
and Norway (Besley et al., 1999; Grepperud and Iversen, 2011; King and Mossialos, 2005). The explanation for this is undoubtedly the Danish legislation, which implies that employees are tax-exempted for the income value of EPHI conditional on the insurance being offered to all employees in the company.

Considering the importance of the various sociodemographic characteristics, the probability of having EPHI was found to increase with income, being employed as a white-collar worker, and age until the age of 49 at a five percent level of significance or below. This means that EPHI generates horizontal inequity in the access to health care services along the dimensions of income, occupation, and age, assuming that the privately insured have preferential access (in the form of shorter waiting time) to some treatments.

On the contrary, the marginal effects of gender, education level, and living in the capital region were found not to be significantly associated with EPHI coverage once the remaining variables were controlled for. Comparing the estimates obtained by the binary and bivariate probit models to the descriptive evidence that males are generally more likely to have EPHI than females and that the privately insured are relative better educated, it appears that the differences in the distributions for these variables is attributable to something else, such as sector of employment. This suspicion is supported by empirical evidence from Norway, where Grepperud and Iversen (2011) found that the coefficients for education and gender lost their significance when dummies for sector of employment were included as explanatory variables. A similar argument applies to living in the capital region, where the larger concentration of knowledge-intensive enterprises in the capital area may be captured by the variables measuring the education level of the employees and to some extent also the size of the workplaces. As expected, membership of the non-profit mutual insurance company 'denmark' is also not associated with the probability of having EPHI, although the two types of private health insurance cover some of the same things.

Considering next the implications of the results for the health-related characteristics, these are less clear-cut. Overall, the group of occupationally active may reasonably be expected to be healthier than pensioners and unemployed, who are unable to take out private health insurance through their workplace by definition. Hence, the targeting of the occupationally active which is implicit in EPHI may be interpreted as cream skimming by the commercial insurers. Restricting the analysis to the workforce, the findings of this study indicate that the relationship between the probability of having EPHI and health is ambiguous. This is in agreement with the major part of the empirical literature. More precisely, the association between EPHI coverage and self-assessed health was found to be quadratic such that individuals in good self-assessed health are more likely to be covered by EPHI than individuals in excellent self-assessed health as well as those in fair, poor or very poor self-assessed health. While the former relationship is consistent with adverse selection into private health insurance by companies with a large share of employees in relatively bad health (in this case good rather than excellent health), the latter might indicate advantageous selection into EPHI. ${ }^{19}$ Alternatively, it may be the result of supply-side restrictions and risk rating of premiums between companies. The relationship between self-assessed health and EPHI coverage revealed in this study does

\footnotetext{
${ }^{19}$ The theory of advantageous selection has found some support in recent studies of the market for supplementary private health insurance (termed Medigap insurance) among the elderly in the US. In particular, the negative relationship between the risk of illness and health insurance coverage has been found to weaken and in some cases change sign when controlling for risk attitude (Cutler et al., 2008) and cognitive capacity (Fang et al., 2008).
} 
not necessarily contradict the previous finding of Kjellberg et al. (2010), that those in good or very good self-assessed health considered jointly are relatively more likely to have EPHI. However, the finer categories add additional nuances. The finding that the probability of having EPHI is largely unaffected by the presence of several chronic conditions suggests that insurance companies do not (and cannot) exclude employees with chronic conditions from obtaining coverage. However, there may still be a deferred period for treatment of existing conditions. One possible explanation for the negative and significant effect of arthritis on the probability of having EPHI is that arthritis could cause some individuals to work part-time, in which case employers would be allowed to exclude them from coverage and maintain the tax exemption (Danish Tax and Customs Administration, 2005).

Finally, assuming that the employer's decision to offer private health insurance may be modelled as an aggregation of the employees' preferences, the negative association between the level of satisfaction with the tax-financed health care system and the probability of having duplicate EPHI suggests that EPHI has succeeded in accommodating differences in preferences across individuals. This is done by allowing individuals who are unsatisfied with the tax-financed health care system to receive treatment at private facilities. However, this interpretation is subject to the reservation that satisfaction with the tax-financed health care system may be endogenous, in which case the observed association cannot be interpreted as a causal effect. Endogeneity may occur if EPHI coverage affects the satisfaction with the tax-financed health care system, e.g. through experience (positive or negative) with private sector treatment. Hence, the only thing that can be inferred for sure is that the probability of having EPHI and the level of satisfaction with the tax-financed health care system are negatively associated.

\section{Concluding remarks}

Overall, it is concluded that individuals who receive fully employer paid EPHI and those who have the premium deducted from their pre-tax income may reasonably be combined in future analyses of EPHI in Denmark, even though the underlying decision processes differ somewhat.

Considering the importance of specific determinants, it is concluded that the characteristics related to the workplace (i.e. sector of employment, size of the workplace, and the presence of a company health scheme) are by far the quantitatively most important determinants. However, the lack of an effect of whether the individual has any subordinates suggests that the special condition of the tax exemption, i.e. that the insurance should be offered to all employees in the company in order to be tax-exempted, has succeeded in preventing companies from offering EPHI exclusively to managerial employees. Given the major importance of employer-related characteristics in determining the probability of EPHI coverage, the employers' decision to offer private health insurance to their employees, including the tradeoffs between EPHI, other fringe benefits, and money wages, are obvious candidates for future research. This would require companylevel data on characteristics such as the age distribution and gender composition of the staff of employees, the composition of the compensation package, how risky the firm sector is, and the profit level of the firm, possibly combined with qualitative interviews of key personnel.

The lack of a clear-cut relationship between health status and the probability of having EPHI suggests that the individuals with EPHI do not systematically belong to companies with a large share of employees in bad health; neither do they select themselves into EPHI in a systematic way based on their probability of falling ill. On the 
contrary, the picture is more clear when it comes to interactions between the public health care system and EPHI, where it is found that individuals with EPHI coverage are on average more unsatisfied with the tax-financed health care system.

Considering the sociodemographic determinants, it is concluded that EPHI generates some extent of horizontal inequity in the access to health care services along the dimensions of income, occupational status, and age, while gender, education level, membership of 'denmark', and living in the capital region are not significantly associated with EPHI coverage. These findings are noted to be robust to various model specifications, and they are not challenged by the various limitations of the study discussed in the previous section.

Brought to a head, the tax-exemption may thus be interpreted as a transfer from low-income workers in the upper and lower age groups to middle-aged individuals employed in highly paid white-collar jobs. It must, however, be emphasized that overall evaluations of the policy of tax-exempting employees for the value of EPHI conditional on the insurance being offered to all employees in the company should also take into account other factors, such as how EPHI influences the use of health care services, sickness absence, and the health of the privately insured, as well as information on the tax revenue lost as a direct consequence of the tax-exemption. ${ }^{20}$ Moreover, it must be kept in mind that this study has shown only that EPHI generates horizontal inequity in the access to health care, which does not necessarily lead to inequity in actual use. EPHI ownership is purely a matter of whether an employee is covered by this type of insurance or not; it does not necessarily imply that the employee agrees with the employer's decision to take out EPHI on his or her behalf, nor that the employee intends to use the insurance to gain access to treatment at a private facility in the case of illness.

Finally, concerns about inequity in the access to health care generated by EPHI may be argued to be based on the underlying assumptions that the treatment received at private facilities is superior to that received at public hospitals, and that the universal taxfinanced health care system is insufficient. These assumptions are debatable in the context of the Danish health care system. In particular, it may be argued that the tax-financed health care system ensures equal access to health care of a sufficient quality for equal need for all citizens, independent of social and economic circumstances. In which case the equity considerations put forward in this paper may be argued to be somewhat redundant (Rodríguez and Stoyanova, 2004).

\section{Acknowledgements}

The collection of the data used in this paper was supported financially by the Danish Health Insurance Foundation (Helsefonden). The paper has benefitted greatly from discussions with Kjeld Møller Pedersen, Jacob Nielsen Arendt, Morten Saaby Pedersen, Ulrika Enemark, participants at the 2010 and 2011 conferences of the Danish Forum for

\footnotetext{
${ }^{20}$ In 2008 when the work on this paper started, the group of individuals with EPHI was largely unexplored territory in Denmark. Since then, the effect of EPHI on the total use of health care services has been explored in a conference paper by the present author and the effect on the use of publicly financed services has been analysed by Søgaard et al. (2011). The effect of EPHI on sickness absence has been analysed in a report published by the Danish Insurance Association (Borchsenius and Hansen, 2010) and a conference paper by Kjeld Møller Pedersen. Finally, the Center for Political Studies (CEPOS) have given their estimate of how EPHI affects the public finances overall (Holstein, 2010).
} 
Health Economics, as well as comments from an anonymous reviewer. Any errors are the responsibility of the author.

* Correspondence to: Astrid Kiil, PhD-student, Research Unit of Health Economics, Institute of Public Health, University of Southern Denmark. Email: kii@sam.sdu.dk 


\section{References}

Aarbu, K. O. (2010). Demand Patterns for Treatment Insurance in Norway. Department of Economics Discussion Paper No. 11/2010. Norwegian School of Economics and Business Administration. http://papers.ssrn.com/sol3/papers.cfm?abstract_id=1589507\&download=yes. Accessed 29 April 2011.

Berinsky, A. (2004). Silent Voices: Opinion Polls and Political Representation in America. New Jersey: Princeton University Press.

Besley, T., Hall, J., \& Preston, I. (1999). The demand for private health insurance: do waiting lists matter? Journal of Public Economics, 72, 155-181.

Bolin, K., Jacobsen, L., \& Lindgren, B. (2002). Employer investments in employee health. Implications for the family as health producer. Journal of Health Economics, 21, 563583.

Borchsenius, V. \& Hansen, J. V. (2010). Er sundhedsforsikrede mindre syge end uforsikrede? (In English: Are health insured less ill than uninsured?). Report 2010:6. The Danish Insurance Association. http://www.forsikringogpension.dk/presse/Statistik_og_Analyse/analyser/Document s/analyserapporten_2010_6.pdf. Accessed 9 May 2011.

Bræmer, M. (2008). Velstillede vælter sig i sundhedsforsikringer (In English: Well-to-do wallow in private health insurances). Newsletter. Ugebrevet A4. http://www.ugebreveta4.dk/da/2008/200841/Baggrundoganalyse/Velstillede_vaelte r_sig_i_sundhedsforsikringer.aspx. Accessed 6 May 2011.

Colombo, F., \& Tapay, N. (2004). Private Health Insurance in OECD Countries: The Benefits and Costs for Individuals and Health Systems. In Towards high-performing health systems: policy studies. Paris: OECD.

Cook, C., Heath, F., \& Thompson, R. L. (2000). A Meta-Analysis of Response Rates in Web- or Internet-Based Surveys. Educational and Psychological Measurement, 60(6), 821-836.

Costa, J. \& Garcia, J. (2003). Demand for private health insurance: how important is the quality gap? Health Economics, 12, 587-599.

Couper, M. P. (2000). Web surveys. A review of issues and approaches. Public Opinion Quarterly, 64(4), 464-494.

Currie, J. \& Madrian, B. C. (1999). Health, health insurance and the labor market. In O. Ashenfelter \& D. Card (Ed.), Handbook of Labor Economics, vol. III (pp. 3309-3416). Elsevier.

Cutler, D. M., Finkelstein, A., \& McGarry, K. (2008). Preference heterogeneity and insurance markets: Explaining a puzzle of insurance. American Economic Review, 98(2), 157-162.

Cutler, D. M. \& Zeckhauser, R. J. (2000). The Anatomy of Health Insurance. In A. J. Culyer \& J. P. Newhouse (Ed.), Handbook of Health Economics, vol. I(part 1) (pp. 564-643). Elsevier. 
Danish Tax and Customs Administration - SKAT. (2005). Sundhedsydelser - når arbejdsgiveren betaler (In English: Health care services - when the employer pays). Leaflet. http://www.skat.dk/getFile.aspx?ld=52854. Accessed 9 May 2011.

Danske Bank (2011). Middelkurser i København, marts 2011 (In English: Average exchange rates Copenhagen, March 2011). http://app.danskebank.dk/dadk/Privat/Dagligoekonomi/Valuta/Documents/Valutaoversigt2011/ValutaMarts2011.pdf. Accessed 27 April 2011.

de Meza, D. \& Webb, D. C. (2001). Advantageous selection in insurance markets. RAND Journal of Economics, 32(2), 249-262.

Fang, H., Keane, M. P., \& Silverman, D. (2008). Sources of advantageous selection: evidence from the Medigap insurance market. Journal of Political Economy, 116, 303350 .

Feldman, R., Dowd, B., Leitz, S., \& Blewett, L. A. (1997). The Effect of Premiums on the Small Firms' Decision to Offer Health Insurance. Journal of Human Resources, 32(4), 635-658.

Goldstein, G. S. \& Pauly, M. V. (1976). Group Health Insurance as a Local Public Good. In R. Rosett (Ed.), The Role of Health Insurance in the Health Services Sector. Cambridge, MA: National Bureau of Economic Research.

Greene, W. H. (1996). Marginal Effects in the Bivariate Probit Model. Department of Economics Working Paper Series EC-96-11. Stern School of Business, New York University. http://papers.ssrn.com/sol3/papers.cfm?abstract_id=1293106. Accessed 6 May 2011.

Greene, W. H. (1999). Models for Discrete Choice. In Econometric Analysis, $5^{\text {th }}$ ed. (pp. 713-719). New Jersey: Prentice Hall.

Grepperud, S. \& Iversen, T. (2011). Hvem har arbeidsgiverfinansiert behandlingsforsikring? (In English: Who has employer-financed treatment insurance?). Tidsskrift for velferdsforskning, 14(1), 15-24.

Grossman, M. (1972). On the Concept of Health Capital and the Demand for Health. Journal of Political Economy, 80(2), 223-255.

Gruber, J. (2000). Health Insurance and the Labor Market. In A. J. Culyer \& J. P. Newhouse (Ed.), Handbook of Health Economics, vol. I(part 1) (pp. 645-706). Elsevier.

Harmon, C. \& Nolan, B. (2001). Health insurance and health services utilization in Ireland. Health Economics, 10(2), 135-145.

Health Insurance denmark (2009). Årsrapport 2009 (In English: Annual report 2009). http://www.sygeforsikring.dk/Default.aspx?ID=23. Accessed 29 April 2011.

Hemenway, D. (1990). Propitious selection. Quarterly Journal of Economics, 105(4), 1063-1069. 
Holstein, M. A. (2010). Sundhedsforsikringer giver en svag forbedring af de offentlige finanser (In English: Health insurances cause a weak improvement of the public finances). Memorandum. Center for Political Studies (CEPOS). https://www.cepos.dk/fileadmin/user_upload/dokumenter/Sundhedsforsikringer_gi ver_en_svag_forbedring_af_de_offentlige_finanser_01.pdf. Accessed 9 May 2011.

Jofre-Bonet, M. (2000). Public health care and private insurance demand: The waiting time as a link. Health Care Management Science, 3, 51-71.

Jones, A. M., Koolman, X., \& Doorslaer, E. v. (2006). The impact of supplementary private health insurance on the use of specialists in selected European countries. Annales d'Economie et de Statistiques, 83-84, 251-275.

Kiil, A., \& Pedersen, K. M. (2009). The Danish Survey on Voluntary Health Insurance 2009. Data documentation: Population, Design, and Descriptive Statistics. Health Economics Papers 2009:3. University of Southern Denmark. http://www.healtheconomics.dk/. Accessed 29 April 2011.

King, D. \& Mossialos, E. (2005). The determinants of private medical insurance prevalence in England, 1997-2001. Health Services Research, 40(1), 195-212.

Kjellberg, J., Andreasen, J. N., \& Søgaard, J. (2010). Private sundhedsforsikringer (In English: Private health insurances). Research Report. Danish Institute for Health Services Research. http://forsiden.3f.dk/assets/pdf/SD192038721.PDF. Accessed 29 April 2011.

Maddala, G. S. (2001). Simultaneous Equations Models. In Introduction to Econometrics, $3^{\text {rd }}$ ed. (pp. 343-389). Chichester: John Wiley \& Sons

Madsen, P. G. H. (2010). Ventelister på landets hospitaler bekymrer danskerne (In English: The Danes worry over hospital waiting lists). Newsletter. Ugebrevet A4. http://www.ugebreveta4.dk/da/2010/201011/Baggrundoganalyse/Vaerdipolitikken_ er_tilbage/Ventelister_paa_landets_hospitaler_bekymrer_danskerne.aspx. Accessed 29 April 2011.

Mossialos, E. \& Thomson, S. M. S. (2002). Voluntary health insurance in the European Union: a critical assessment. International Journal of Health Services, 32, 19-88.

Nyman, J. A. (1999). The value of health insurance: The access motive. Journal of Health Economics, 18, 141-152.

Nørredam, M. \& Christiansen, T. (2010). Ulighed i adgangen til sundhedsydelser (In English: Inequity in the access to health care services). Journal of The Danish Medical Association, 172(19), 782-784.

http://www.ugeskriftet.dk/LF/UFL/2010/10/pdf/VP09090423.pdf. Accessed 14 June 2011.

OECD (2004). Proposal for a taxonomy of health insurance OECD Study on Private Health Insurance. Working document. OECD Health Project. http://www.oecd.org/dataoecd/24/52/31916207.pdf. Accessed 29 April 2011.

OECD (2009). Health at a Glance 2009: OECD Indicators. Report. http://www.oecd.org/dataoecd/55/2/44117530.pdf. Accessed 29 April 2011.

OECD (2010). Health Data: Health expenditure by financing agent/scheme. Data tables. http://www.oecd.org/dataoecd/46/36/38979632.xls. Accessed 3 May 2011. 
Olivella, P. \& Vera-Hernández, A. M. (2006). Testing for Adverse Selection into Private Medical Insurance. Working Paper 06/02. The Institute for Fiscal Studies, London. http://www.ifs.org.uk/wps/wp0602.pdf. Accessed 6 May 2011.

Propper, C. (1989). An econometric analysis of the demand for private health insurance in England and Wales. Applied Economics, 21, 777-792.

Propper, C. \& Green, K. (2001). A Larger Role for the Private Sector in Financing UK Health Care: the Arguments and the Evidence. Journal of Social Policy, 30(4), 685704.

Propper, C., Rees, H., \& Green, K. (2001). The demand for private medical insurance in the UK: A cohort analysis. Economic Journal, 111, 180-200.

Rodríguez, M. \& Stoyanova, A. (2004). The effect of private insurance access on the choice of GP/specialist and public/private provider in Spain. Health Economics, 13(7), 689-703.

Rodríguez, M. \& Stoyanova, A. (2008). Changes in the demand for private medical insurance following a shift in tax incentives. Health Economics, 17(2), 185-202.

Rothschild, M. \& Stiglitz, J. E. (1976). Equilibrium in Competitive Insurance Markets: An Essay on the Economics of Imperfect Information. Quarterly Journal of Economics, 90(4), 630-649.

Seim, A., Løvaas, L., \& Hagen, T. P. (2007). Hva kjennetegner virksomheter som kjøper private helseforsikringer? (In English: What characterises companies that purchase private health insurance?). Tidsskrift for Den norske legeforening, 20(127), 26732675.

Sheehan, K.B. (2006). E-mail Survey Response Rates: A Review. Journal of ComputerMediated Communication, 6(2).

Statistics Denmark (2009a). Befolkningens brug af internet 2009 (In English: Population internet use 2009). Publication. http://www.dst.dk/pukora/epub/upload/14039/it.pdf. Accessed 29 April 2011.

Statistics Denmark (2009b). LON01: Earnings for employees in the private sector by education, group of employees, components and sex. LON31: Earnings for central government employees by education, components and sex. LON44: Earnings for local government employees by industry, components and sex. Data tables. http://www.statistikbanken.dk/statbank5a/default.asp?w=1280. Accessed 28 February 2011.

Statistics Denmark (2010). AKU1: Population (15-66 years) in thousands by labour status, age and sex. BEF05 (18-75). Data tables. http://www.statistikbanken.dk/statbank5a/default.asp?w=1280. Accessed 29 April 2011.

Strandberg-Larsen, M., Nielsen, M. B., Vallgårda, S., Krasnik, A., \& Mossialos, E. (2007). Denmark: Health system review. Health Systems in Transition, 9(6), 1-164. 
Søgaard, R., Bech, M. \& Olsen, J. (2011). Effekten af private sundhedsforsikringer på forbruget af offentligt finansierede sygehusydelser (In English: The effect of private health insurances on the use of publicly financed hospital services). Report. Centre for Applied Health Services Research and Technology Assessment (CAST), University of Southern Denmark. http://static.sdu.dk/mediafiles//B/3/B/\%7BB3B3D963-4A0A490A-B735-23D62DB153B8\%7DRapport\%20sundhedsforsikringer.pdf. Accessed 9 May 2011.

The Danish Insurance Association (2010). Sundhedsforsikringer - hovedtal 2003-2009. (In English: Health insurance - key figures 2003-2009). Data tables. http://www.forsikringogpension.dk/presse/statistik_og_analyse/statistik/forsikring/a ntal/sider/sundhedsforsikring_antal_forsikrede_praemier_erstatninger.aspx. Accessed 29 April 2011.

The Danish parliament (2002). L97 (oversigt): Forslag til lov om ændring af ligningsloven. (Skattefrihed for arbejdsgiverbetalte sundhedsbehandlinger). http://webarkiv.ft.dk/?/Samling/20012/lovforslag_oversigtsformat/L97.htm. Accessed 7 May 2011.

Van de Ven, W. P. M. M. \& Van Praag, B. M. S. (1981). The Demand for Deductibles in Private Health Insurance. Journal of Econometrics, 17, 229-252.

YouGov Zapera Ltd (2009). Panel Methodology. http://www.yougov.dk/Aboutus/PanelMethodology.aspx. Accessed 20 August 2009 